\title{
Dynamics of $\mathrm{pH}$-sensitive nitroxide radicals in water adsorbed in ordered mesoporous molecular sieves by EPR Spectroscopy
}

\author{
Elena G. Kovaleva ${ }^{\mathrm{a}, *}$, Leonid S. Molochnikov ${ }^{\mathrm{b}}$, Elena L. Golovkina ${ }^{\mathrm{b}}$, Martin Hartmann ${ }^{\mathrm{c}}$, Igor. A. Kirilyuk ${ }^{\mathrm{d}}$, \\ Igor. A. Grigor'ev ${ }^{\mathrm{d}}$ \\ a Institute of Chemical Engineering, Ural Federal University, Mira St., 19, 620002 Yekaterinburg, Russia \\ ${ }^{\mathrm{b}}$ Department of Inorganic and General Chemistry, Ural State Forest Engineering University, Siberian Highway, 37, 620100 Yekaterinburg, Russia \\ ' Erlangen Catalysis Resource Center (ECRC), Friedrich-Alexander Universität Erlangen-Nürnberg, Egerlandstraße 3, 91058 Erlangen, Germany \\ ${ }^{\mathrm{d}}$ Institute of Organic Chemistry, Siberian Branch of the Russian Academy of Sciences, Akad. Lavrent'ev Av. 9, 630090 Novosibirsk, Russia
}

\section{A R T I C L E I N F O}

\section{Article history:}

Received 7 January 2013

Received in revised form 7 May 2013

Accepted 21 May 2013

Available online 31 May 2013

\section{Keywords:}

Ordered mesoporous materials

pH-sensitive nitroxide radicals

Fast (slow) radical motion

EPR spectroscopy

\begin{abstract}
A B S T R A C T
A spin pH probe technique was used to study the influence of the channel diameter on the EPR spectra of $\mathrm{pH}$-sensitive nitroxide radicals (NR) located in the channels of the mesoporous molecular sieves MCM-41 and SBA-15 with diameters ranging from 2.3 to $8.1 \mathrm{~nm}$. From EPR spectra analysis and the results of the $\mathrm{NR}$ retention by the mesoporous molecular sieves upon washing with an aqueous $\mathrm{KCl}$ solution, the regularities of NR molecular location inside the channels were studied. The obtained dependence of the fraction of the radical molecules in the fast motional regime (with the rotational correlation times, $\tau_{c}=2 \times 10^{-11} \mathrm{~s}-9 \times 10^{-11} \mathrm{~s}$ ) in the channels of the mesoporous molecular sieves as a function of pH indicates that both NR in the fast and slow motional regime (with $\tau_{c}=8 \times 10^{-9} \mathrm{~s}-7 \times 10^{-10} \mathrm{~s}$ ) may be used for estimation of the solution acidity inside the channels and of the near-surface electrical potential.
\end{abstract}

(c) 2013 Elsevier Inc. All rights reserved.

\section{1.Introduction}

Ordered mesoporous molecular sieves (MMS) such as MCM-41 and SBA-15 are porous inorganic materials with a strictly ordered spatial structure; however, the walls are amorphous and the atoms do not compose a crystalline lattice. The ordered structure of MCM-41 and SBA-15 is a honeycomb type hexagonal array of regular non-crossing pores-channels with a narrow pore size distribution. The walls of the channels have a definite thickness and are constituted of amorphous $\mathrm{SiO}_{2}$ [1,2]. The channel diameter can be tuned from 3 to $50 \mathrm{~nm}$ depending on the synthesis conditions [3]. The channel length (sieve particle size) is $1-10 \mu \mathrm{m}[4,5]$ and exceeds the channel diameter more than 1000 times.

Generally, the MMS synthesis is carried out by self-organized structure assembly from an inorganic component at the micellar surface of the surface-active substance (SAS) [6].

The chemical properties of the mesoporous materials are determined to a large extent by the properties of the functional groups located on their surface. Three types of functional groups

\footnotetext{
* Corresponding author.

E-mail addresses: gek1969@bk.ru, elenakovaleva1969@gmail.com(E.G. Kovaleva), lsmolochnikov@gmail.com (L.S. Molochnikov),golovkina_e.l@mail.ru (E.L. Golovkina), martin.hartmann@ecrc.uni-erlangen.de (M. Hartmann), kirilyuk@nioch.nsc.ru (Igor. A. Kirilyuk), grig@nioch.nsc.ru (Igor. A. Grigor'ev).
}

characteristic for the silica surfaces, in particular silanol silanediol, and siloxane groups are present [7-9]. The number of silanol groups on the inner surface of the mesoporous molecular sieves may be up to 6 groups $\mathrm{nm}^{-2}$ [3].

The hydroxylated silica surface has the point of zero charge (PZC) at $\mathrm{pH} \sim 2-3[10]$. At higher $\mathrm{pH}$ values, the surface reveals weak acid properties and possesses a slight negative charge. The $\mathrm{p} K_{a}$ value of the silanol groups is approximately equal to 6 . Therefore, at $\mathrm{pH} \sim 6$ their ionization degree increases significantly, thus rising the surface negative electrical charge (SEP). Moreover, at $\mathrm{pH}>7-8$ the silica solubility increases noticeable [10].

The water state in micropores and its acid-base characteristics are known to differ from that of the external solution surrounding the solid samples [11-14]. The electron paramagnetic resonance (EPR) spectrum of nitroxide radicals is very sensitive to changes in the radical composition and parameters of its surroundings. Interaction of probe molecules with oxide surfaces depends both on the molecular structure and the surface type, thus changing the EPR parameters [15]. Therefore, NR can be used to study the characteristics of their surrounding, solvent molecules and the surface characteristics of the solid support they are absorbed on. EPR spectra of the nitroxides of different size were loaded into mesoporous materials with different channel diameter in order to obtain information on the dynamics of an organic spin probe in water adsorbed in pores of varying size. Moreover, we want to explore the possibility of using $\mathrm{pH}$-sensitive nitroxide radicals in 
mesoporous molecular sieves for measuring the $\mathrm{pH}$ inside the channels and the near-surface electrical potential.

\section{Experimental section}

\subsection{Reagents, probes and materials}

The inorganic reagents used for the materials synthesis were of analytical quality and were used as obtained. Double-distilled water was employed in all experiments. The nitroxide radicals used (Table 1) were synthesized at the Institute of Organic Chemistry, Siberian Branch of the Russian Academy of Sciences (Novosibirsk) $[16,17]$.

All-silica MCM-41 materials with different pore diameters were synthesized using dodecyltrimethylammonium bromide $\left(\mathrm{C}_{12}\right.$ MCM-41) and hexadecyl trimethylammonium bromide $\left(C_{16}\right.$ MCM-41), respectively, as reported in our previous papers [1820]. The SBA-15 materials was synthesized by employing the tribloc copolymer poly(ethylene glycol)-bloc-poly(propylene glycol)-bloc-poly(ethylene glycol) (Pluronic P123, molecular weight $5800, \mathrm{EO}_{20} \mathrm{PO}_{70} \mathrm{EO}_{20}$ ) as reported in the literature [21].

\subsection{Characterization}

The X-ray powder diffraction patterns were recorded on a Siemens D5005 diffractometer with use of $\mathrm{Cu} \mathrm{K}_{\alpha}$ radiation $(\lambda=0.154 \mathrm{~nm})$. Nitrogen adsorption and desorption isotherms were measured at $77 \mathrm{~K}$ on a Quantachrome Autosorb 1 sorption analyzer. All samples were outgassed at $513 \mathrm{~K}$ for $3 \mathrm{~h}$ prior to the adsorption measurements. The specific surface area was obtained by using the standard Brunauer-Emmett-Teller (BET) method, while the pore size distribution was calculated from the adsorption branch of the isotherm by using the Nonlocal Density Functional Theory (NLDFT). The textural parameters of the samples under study are collected in Table 2.

The EPR spectra of nitroxide radical in bulk solution and adsorbed in the channels of the solid samples were recorded by an Bruker ElexSys 580 pulsed FT-EPR EPR-spectrometer and an automatic X-band ADANI PS-100.X spectrometer (Advanced Analytical Instruments Inc., Belarus) at 293 and $77 \mathrm{~K}$. Optimal conditions of microwave frequency power and modulation amplitude of magnetic field were chosen for recording of the EPR spectra. EPR spectra of vitrified radical solutions were recorded at $77 \mathrm{~K}$ for simulating hyperfine splitting constants $\left(a_{x x}, a_{y y}, a_{z z}\right)$ of an anisotropic signal. Glycerol in amounts of $20 \%$ by volume was used as a vitrifying agent.

The spectra of the solutions were recorded using quartz ampoules containing a capillary. Unsealed Quartz ampoules with an internal diameter of $3.5 \mathrm{~mm}$ were used for the solid samples. In order to record the EPR spectra of the MMS, the solid samples were separated from the solution by filtration. The solvent film was removed from the surface of the particles by drying with filter paper prior to recording of the spectrum. It should be noted that an EPR spectrum of NR in the MMS studied was found to be the same both for the samples separated from the solution by filtration with filter

Table 1

Used nitroxide radicals ${ }^{\mathrm{a}}$ and their characteristics.

\begin{tabular}{|c|c|c|c|c|c|}
\hline \multirow[t]{2}{*}{ Radical } & \multirow[t]{2}{*}{ Structural formula } & \multirow[t]{2}{*}{$\mathrm{p} K$} & \multirow[t]{2}{*}{ Sizes $^{\mathrm{b}}$, A length $\times$ height $\times$ width } & \multicolumn{2}{|c|}{$a_{N} \pm 0.05, \mathrm{G}$} \\
\hline & & & & $\mathrm{RH}^{+}$ & $\mathrm{R}$ \\
\hline $\mathrm{R} 1$ & & $\begin{array}{l}\mathrm{p} K_{a 1}=2.92 \\
\mathrm{p} K_{a 2}=5.06\end{array}$ & $7.1 \times 6.7 \times 7.1$ & 13.94 & 15.20 \\
\hline $\mathrm{R} 2$ & & $\mathrm{p} K_{a}=5.9$ & $7.1 \times 6.6 \times 7.2$ & 14.62 & 15.46 \\
\hline R3 & 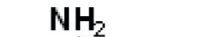 & $\mathrm{p} K_{a}=6.1$ & $6.2 \times 5.4 \times 4.4$ & 14.96 & 15.76 \\
\hline
\end{tabular}



b The sizes of radical molecules were determined by the molecular mechanics method using Hiper Chem Pro 6.03 (Hypercube Inc., 2000 ).
} 
Table 2

Textural parameters of the MMS used in this study.

\begin{tabular}{llll}
\hline MMS & $\begin{array}{l}\text { Average pore } \\
\text { diameter } \\
\pm 0.1, \mathrm{~nm}\end{array}$ & $\begin{array}{l}\text { Specific } \\
\text { surface } \\
(\text { ABET }) \pm 10, \mathrm{~m}^{2} / \mathrm{g}\end{array}$ & $\begin{array}{l}\text { Overall pore } \\
\text { volume } \\
\pm 0.01 \mathrm{~cm}^{3} / \mathrm{g},\end{array}$ \\
\hline $\mathrm{SBA}-15$ & 8.1 & 550 & 1.17 \\
$\mathrm{C}_{12}$ MCM-41 & 2.3 & 1210 & 0.70 \\
$\mathrm{C}_{16}$ MCM-41 & 3.2 & 1080 & 0.86 \\
\hline
\end{tabular}

paper and by centrifugation. The spectra were recorded immediately after this procedure (i.e., no time was allowed for the MMS to dry). The $\mathrm{pH}$ values of the NR bulk solutions and those in the solutions surrounding the sieve samples (external solutions) were measured directly by a " 1 in 3 " combined electrode with a model Symphony S20-K pH-meter with an accuracy of $\pm 0.02 \mathrm{pH}$ units. The concentrations of the nitroxide radicals in solutions were kept below $0.5 \mathrm{mM}$ in order to avoid broadening the EPR spectral lines due to the concentration effects [22].

\subsection{Preparation of the samples for EPR study}

Potentiometric titration of the studied MMS was performed by a conventional batch multisample technique $[11,12,23]$. The ratio between the amounts of MMS and NR solution was $1: 100 \mathrm{~g} / \mathrm{ml}$. The ionic strength $(\mu)$ was adjusted to 0.1 with $\mathrm{KCl}$. The studied MMS were kept in the NR solutions up to establishing the dynamic equilibrium between the external solution and the solution inside the channels (intrinsic). Thereafter, the $\mathrm{pH}$-values of equilibrium external solutions $(\mathrm{pH})$ were measured.

\subsection{NR EPR spectral processing and simulation}

Depending on the $\mathrm{pH}$ of the solution, NR exist in their protonated $\left(\mathrm{RH}^{+}\right)$, deprotonated ( $\left.\mathrm{R}\right)$ and intermediate (mixed) forms. As the hyperfine splitting constants $\left(a_{N}\right)$ for these forms are different (Table 1), a pH rise would results in an increase in the distance between the first and the second components of the triplet in the corresponding EPR spectrum (a). Therefore, the parameter $a$ is $\mathrm{pH}-$ sensitive and characteristic for the superposition of protonated and deprotonated forms of the NR. The obtained experimental spectra were processed using Microcal Origin 6.1. The numeric data of the normalized experimental spectra were exported to a text file required for further spectra simulating using the program developed by Freed and coworkers described in [24].

The parameter $f$, as a fraction of the molecules of NR in the slow motion regime (with the rotational correlation times, $\tau_{c}=8 \times$ $10^{-9} \mathrm{~s}-7 \times 10^{-10} \mathrm{~s}$, so called "slow-motional" molecules of NR) in the deprotonated form, was used as the $\mathrm{pH}$-sensitive parameter of an anisotropic EPR spectrum. The $f$ parameter was determined by simulating the experimental spectra using the above-mentioned program [24]:

$f=\frac{n_{R}}{\left(n_{R}+n_{R H^{+}}\right)}$

where $n_{R}$ and $n_{R H^{+}}$are the fractions of the "slow-motional" NR molecules in the deprotonated and protonated forms, respectively.

The first step in EPR spectra simulation was the determination of the Spin Hamiltonian parameters and NR rotational characteristics in the protonated (at $\mathrm{pH} \leqslant 1.5$ for $\mathrm{R} 1$, at $\mathrm{pH} \leqslant 3$ for $\mathrm{R} 2$ and $\mathrm{R} 3$ ) and deprotonated $($ at $\mathrm{pH} \geqslant 9$ ) forms in the channels of the molecular sieve. At this $\mathrm{pH}$, the EPR spectrum is composed from the superposition of only two signals: from the "slow motional " nitroxides and from the radicals in the fast-motion regime (with the correlation times, $\tau_{c}=2 \times 10^{-11} \mathrm{~s}-9 \times 10^{-11} \mathrm{~s}$, so called "fast-motional" mole- cules of NR), respectively, being either in the protonated $\left(\mathrm{RH}^{+}\right)$or deprotonated (R) form. Other EPR spectra of NR in the channels of the molecular sieves studied (from 1.5(3) to $9 \mathrm{pH}$ units) consist of a superposition of four signals of NR namely of the "fast- and slow-motional" radicals, respectively, existing both in the $\mathrm{RH}^{+}$ and $\mathrm{R}$ forms.

Freed's program allows to use only three theoretical spectra for simulating an experimental one. EPR spectra of NR adsorbed in the MMS channels obtained during the experiment at $1.5(3)<\mathrm{pH}<9$ were simulated using the following three signals: the signals given by the "fast- and slow-motional" radicals in the protonated and in the deprotonated form, respectively, and the average signal given by the "fast-motional" NR molecules.

It should be noted that the Spin Hamiltonian parameters of the average isotropic signal, representing the superposition of the signals of the "fast-motional" radical molecules in the protonated and deprotonated forms, calculated as a result of this procedure, have no physical meaning. But all the necessary information on this type of molecules was obtained by direct calculations of the pH-sensitive parameter $a$ from EPR spectra.

The experimental and calculated spectra are found not to match completely (Fig. 1), but since the correlation coefficient exceeded 0.95 , the fit was considered satisfactory (see Supplementary data). This confirms that a correlation between the data of the simulated and experimental EPR spectra indeed exists. Therefore, the data obtained may be used for plotting reliable curves of titration $f=\mathrm{F}(\mathrm{pH})$. According to our estimations using the above-mentioned simulation, the error in determination of the fractions of the "fastmotional" NR molecules $(q)$ and the "slow-motional" radicals in the deprotonated form $(f)$ does not exceed $3 \%$.

\subsection{Experiments on the retention of $N R$ by the MMS}

Initial air-dried MMS $\mathrm{C}_{12} \mathrm{MCM}-41$ and $\mathrm{C}_{16} \mathrm{MCM}-41$ samples were prepared for the experiment as described above for potentiometric titration. First, the EPR spectra of the MMS impregnated with R1 were recorded. The ratio between the amount of MMS and the amount of NR solution was fixed to $1: 100 \mathrm{~g} / \mathrm{ml}$ and the above-mentioned MMS were washed with $1 \mathrm{ml}$ portions of a solution of $\mathrm{KCl}$ (ionic strength, $\boldsymbol{\mu}=0.1$, $\mathrm{pH}$ adjusted with $\mathrm{HCl}$ ). EPR spectra were recorded after each washing step. The height of the lowfield component of the radical isotropic spectrum $(J)$ was measured as shown in Fig. 1a. $J_{0}$ is the initial height before washing.

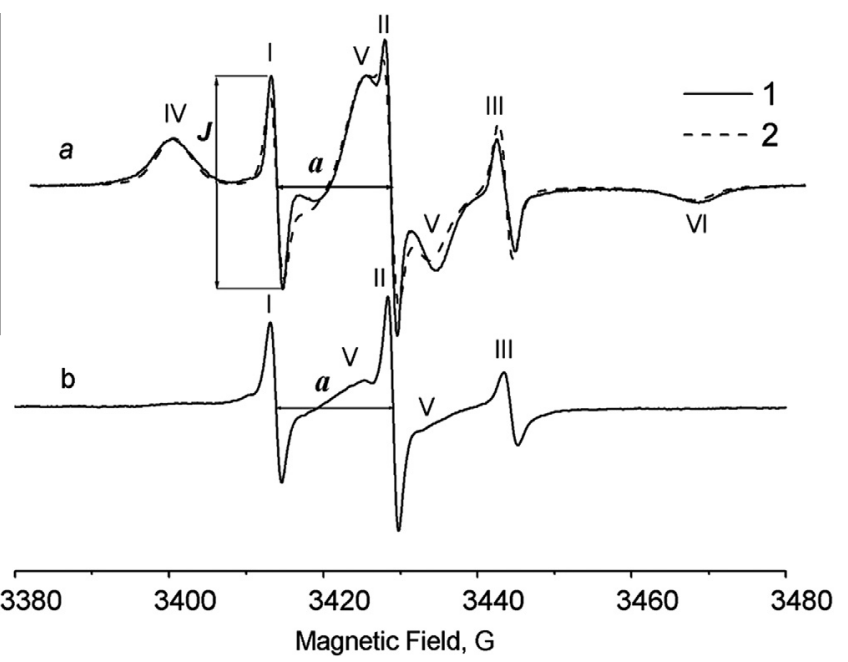

Fig. 1. Representative EPR spectra of NR R1, R2 (a) and R3 (b) in the channels of SBA-15 at $293 \mathrm{~K} \mathrm{pH}=6.22$ : (1) experimental spectrum, (2) spectrum simulated using Freed's program [24]; I, II, and II - signals of isotropic spectrum; IV, V, and VI signals of anisotropic spectrum. 
For the anisotropic spectra of NR in MMS the fraction of anisotropic signal after passing each $1 \mathrm{ml}$ of a solution of $\mathrm{KCl}(\boldsymbol{k}, \%)$ was determined by simulating the experimental EPR spectra. After factorization of the initial EPR spectrum of R1 in the MMS studied (before washing), the parameter $\omega$, which characterizes the fraction of the "slow-motional" NR, was defined using formula (2):

$1-q=w$

The intensities of the anisotropic spectrum of NR during washing of MMS with $\mathrm{KCl}$ solution $\left(I_{a}\right)$ decrease and can be calculated using Eq. (3):

$I_{a}=I_{i, a}-I_{i} \times J / J_{0}$

where $I_{i, a}, I_{i}$ and $I_{a}$ are the intensities of the normalized initial EPR spectrum of NR, only isotropic and only anisotropic components during washing MMS with $\mathrm{KCl}$, respectively. The parameter $k$ was calculated from manipulation with simulated initial anisotropic EPR spectra of NR $\left(I_{a 0}\right)$ and those after passing the corresponding portions of $\mathrm{KCl}$ solution $\left(I_{a}\right)$ by Eq. (4):

$k=I_{a} / I_{a 0} \times 100 \%$

\section{Results}

3.1. EPR spectra of nitroxide radicals adsorbed in the MMS as a function of $\mathrm{pH}$

The majority of the EPR spectra of the NR adsorbed in the channels of the materials studied in this work consist of a superposition of isotropic and anisotropic signals (Fig. 1a and b), which proves the coexistence of two types of molecular mobility (fast and slow motion) when the nitroxide radicals employed in this study are located in the channels of nanoporous materials.

At high $\mathrm{pH}(\mathrm{pH} \geqslant 10)$, the NR used in our study located inside the channels of the mesoporous support exhibit the EPR spectra characteristic only for the "fast-motional" NR regardless of their size [25] (Fig. 2). They were similar to the characteristic spectrum for NR in bulk water solution [12]. Therefore, their limited mobility at lower $\mathrm{pH}$ is presumably not due to their limited mobility in the narrow channels in the mesoporous molecular sieves.

3.2. EPR spectroscopic monitoring of retention of NR by MMS while washing with a $\mathrm{KCl}$ aqueous solution

Our experiments on the retention of the radical $\mathrm{R} 1$ by $\mathrm{C}_{12} \mathrm{MCM}-$ $41(d=2.3 \mathrm{~nm})$ and $\mathrm{C}_{16} \mathrm{MCM}-41(d=3.2 \mathrm{~nm})$ showed that at high



Fig. 2. Representative ESR spectrum of NR R1 in the channels of the $C_{12} M C M-41$ at $\mathrm{pH}=10.53$.
$\mathrm{pH}=10.9$ this radical is removed completely from the channels with relatively small volumes of aqueous $\mathrm{KCl}$ solutions at the same $\mu$ and $\mathrm{pH}$ at which the samples were saturated with the radical (Fig. 3).

With decreasing $\mathrm{pH}$ of the solutions to $\mathrm{pH} 8.64$ ( $\mathrm{R} 1$ remains in electro neutral form), the radical removal from the mesoporous materials is hindered and a significantly larger volume of the solution is required for their complete removal. Thus, the interaction of the NR with the silica surface is different at $\mathrm{pH}=10.9$ and 8.64.

On the other side, at $\mathrm{pH}=4.2$ approximately $30 \%$ of the radical molecules located in $\mathrm{C}_{12} \mathrm{MCM}-41$ are not removed by washing with an aqueous $\mathrm{KCl}$ solution. Therefore, we assume that the reason for slow motion for at least a fraction of the probe molecules is their direct interaction with the surface.

The similar trend of the dependences of $I_{i}$ and $I_{a}$ on the volume of solutions that were passed through the MMS, was revealed for the "fast- and slow-motional" molecules of NR R1, respectively (Fig. 3a and b).

\subsection{A fraction of the "fast-motional" NR in the MMS (q) vs. pH}

The dependences $q=\mathrm{f}(\mathrm{pH}$ ) (Fig. 4) are found to be cup-shaped; this is especially visible for NR in the SBA-15 channels (Fig. 4a). The parameter $q$ NR initially falls with decreasing $\mathrm{pH}$ and then passes through a minimum. Thereafter the contribution increases again with the reduction in alkalinity and a rise of acidity, respectively.

The parameter $q$ for R1 and R2 increases with rising acidity slower as compared to R3 (Fig. 4), probably as a consequence of their larger size.

The $q$-values for R1 and R2 in the mesoporous channels with quite different pore diameters (SBA-15 $(d=8.1 \mathrm{~nm})$ and MCM-41 $\left(d=2.3\left(C_{12}\right)\right.$ and $\left.3.2 \mathrm{~nm}\left(C_{16}\right)\right)$ are very similar and typically below $10 \%$ at pH 5-7. For NR R3 radical, this parameter is significantly larger and makes up more than 40\% for SBA-15 (Fig. 4).

\section{Discussion}

\subsection{EPR testing of NR in the silica-based materials by other researchers}

A coexistence of two signals ascribed to the "fast- and slowmotionial" NR on a silica gels surface was also reported by Martini

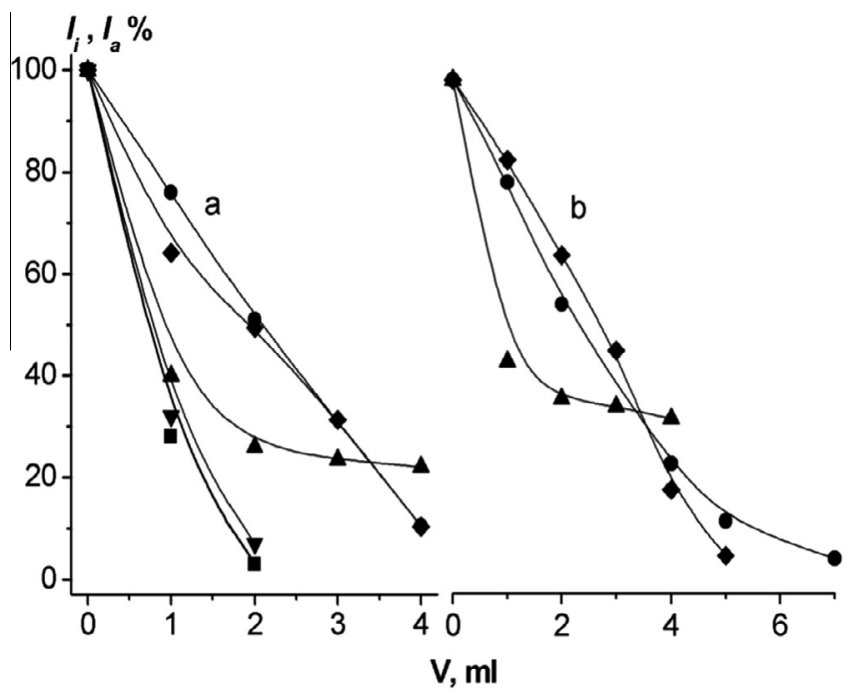

Fig. 3. Retention of $\mathrm{R} 1$ by MMS while washing with an aqueous solution of $\mathrm{KCl}$ with ionic strength 0.1 with different $\mathrm{pH}$ (adjusted by $\mathrm{HCl}$ or $\mathrm{KOH}$ ). Dependences of the intensities of the normalized isotropic $I_{i}$ (a) and anisotropic $I_{a}$ components (b) of the NR EPR spectra on the volume of the washing solution passed $C_{12}$ MCM-41 at $\mathrm{pH}=10.92(\boldsymbol{\nabla}), \mathrm{pH}=8.64(\bullet)$ and at $\mathrm{pH}=4.23(\boldsymbol{\Delta}) ; \mathrm{C}_{16} \mathrm{MCM}-41$ at $\mathrm{pH}=10.92(\boldsymbol{\nabla})$, $\mathrm{pH}=8.64(\bullet)$ 

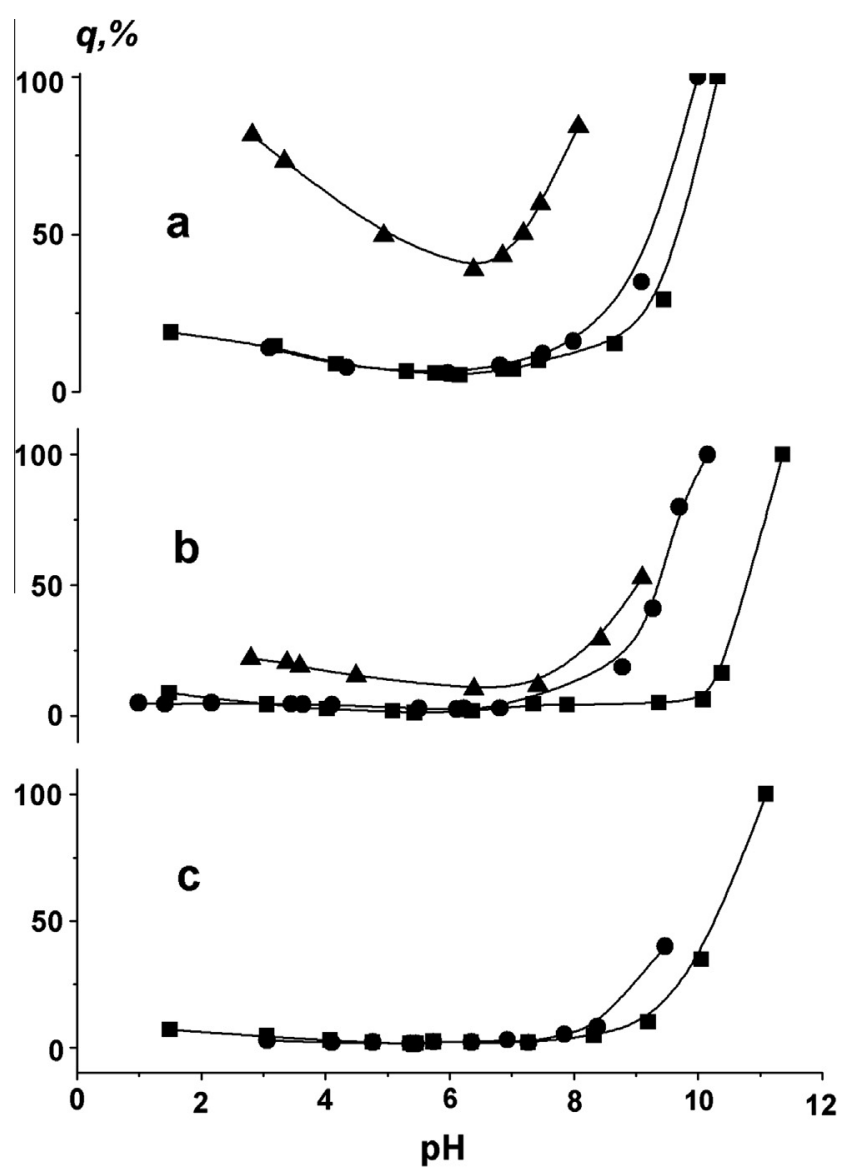

Fig. 4. Changes in fraction of the "fast-motional" molecules of NR R1 (घ, R2( $)$, R3 ( $\mathbf{\Delta}$ in the channels of sieves $(q)$ at $293 \mathrm{~K}$ in: (a) SBA-15; (b) $C_{12}$ MCM-41, (c) $C_{16}$ MCM-41.

et al. [26-29] and Samoilova et al. [30,31]. However, Okazaki and Toriyama observed only the signal ascribed to the "slow-motional" NR radicals inside the MCM-41 channels in water and other solvents at room temperature [32-35]. The method of filling the channels with the NR solution employed in their work assumed filling of the channels for more than $80 \%$ by volume (calculated on the basis of an increase of the MCM- 41 powder weight and free volume) [32]. The obvious discrepancy in the shape of the EPR spectra recorded in our work (in particular with respect to number of the signals observed) with the data reported by Okazaki and Toriyama is tentatively ascribed to the different methods used for the channel filling. Morishidge and Nobuoka studied frozen and melted water in the channels of MCM-41-type molecular sieve [36]. They showed that the quantity of water, adjoining the pore surface, is $65 \%$ larger than that in the internal pore volume of the MMS sample with a channel diameter of ca. $3 \mathrm{~nm}$. Probably, the water is adsorbed on the surface only and, thus only the EPR signal given by the "slow-motional" radicals was recorded [32].

At $\mathrm{pH} \geqslant 10$, Martini et al. in agreement with our work also observed no signal characteristic for the "slow-motional" NR, while transiting from positively charged and electro neutral spin probes to negatively charged ones [28]. This effect was explained by mutual repulsion of the negatively charged probes and the negatively charged surface of the silica gel. However, the reasons for the expulsion of the electro neutral probes from the narrow near-surface layer of the negatively charged sieve existing in our case remain unclear. Probably, as suggested by Ayler [10], silica dissolution occurs at such high $\mathrm{pH}$ resulting in sample degradation.
Martini et al. concluded that the observed signals of the "slowmotional" radicals are mainly due to a decrease in water mobility [29]. They suggested that a direct interaction of the spin probe with the silica gel surface is unlikely. Their conclusion is supported by the fact that NR are easily removed from the silica surface by washing with water.

\subsection{Dynamic equilibrium between the "fast - and slow-motional NR"} inside the channels of MMS

The similar trend of the dependences of $I_{i}$ and $I_{a}$ on the volume of solutions that were passed through the MMS shown in Fig. 3a and $\mathrm{b}$ is caused, apparently, by the dynamic equilibrium inside the channels between the NR with one or another form of motion. The presence of the hard-to-remove "fast-motional" radical molecules being in equilibrium with the "slow-motional" molecules may be interpreted as direct evidence for their location inside the MCM-41 channels. Similar results on the molecular mobility of water (not radicals) in the channels of molecular sieves were reported in a recent neutron scattering study [37].

The observed change of type of motion for the used radicals from slow to fast at $\mathrm{pH}$ values of the external solution larger than seven (alkaline range) provides an additional argument for the assumption of a dynamic equilibrium inside the channels (Fig. $4 \mathrm{a}-\mathrm{c}$ ). This effect can be explained by the differences in $\mathrm{p} K_{a}$ of the radicals and the presence of massive hydrophilic and hydrophobic substituents in the structures of R1 and R2, respectively.

The observed change of the type of motion for R1, which possesses a $K_{a}$ value smaller than $\mathrm{R} 2$ and $\mathrm{R} 3$, to fast motion at higher $\mathrm{pH}$ values may be caused by interaction of the pyridine group with some (acidic) sorption sites on the pore surface of the ordered MMS (Table 1).

\subsection{Interpretation of the changes in the Parameter $q$ with $p H$}

The cup-shaped dependences $q=\mathrm{f}(\mathrm{pH})$ in Fig. 4, in our opinion, is a consequence of the equilibria shown in (5) or (6), which depend on the ratio of $\mathrm{p} K_{a}$ values for the silanol groups of the silica support and the nitroxide radicals:

$\mathrm{R}+\mathrm{O}^{-}-\mathrm{Si}<\underset{\mathrm{OH}^{-}}{\stackrel{\mathrm{H}^{+}}{\rightleftharpoons}} \mathrm{RH}^{+} \ldots \mathrm{O}^{-}-\mathrm{Si} \leftarrow \underset{\mathrm{H}^{+}}{\stackrel{\mathrm{OH}^{-}}{\rightleftharpoons}} \mathrm{R}-\mathrm{H}^{+} \ldots \mathrm{H}-\mathrm{O}-\mathrm{Si} K$

$\mathrm{R}+\mathrm{O}^{-}-\mathrm{Si}<\underset{\mathrm{H}^{+}}{\stackrel{\mathrm{OH}^{-}}{\rightleftharpoons}} \mathrm{R} \ldots \mathrm{H}-\mathrm{O}-\mathrm{Si}<\underset{\mathrm{OH}^{-}}{\stackrel{\mathrm{H}^{+}}{\rightleftharpoons}} \mathrm{R}-\mathrm{H}^{+} \ldots \mathrm{H}-\mathrm{O}-\mathrm{Si}<$

where $\mathrm{R}-\mathrm{H}^{+}, \mathrm{R}$ and $\mathrm{H}-\mathrm{O}-\mathrm{Si} \leq, \mathrm{O}^{-}-\mathrm{Si} \leq$ are the protonated and deprotonated forms of the radicals and silanol groups of the MMS surface, respectively.

The equilibrium (5) corresponds to the case where the $\mathrm{p} K_{a}$ values of the silanol groups are lower than those of the radical. The equilibrium (6) describes the opposite case.

In order to form hydrogen bonds between the radicals and the silanol groups, the NR has to be located in close vicinity to the surface, i.e. should be transferred from the center of the channels to the near-surface adsorptive layer. The mobility in the near surface layer is limited and, thus, the parameter $q$ decreases significantly. At $\mathrm{pH}=4.2$, the mobility of the radical in the molecular sieves is reduced, causing an increase in the retention upon washing with an aqueous $\mathrm{KCl}$ solution (Fig. 3).

A similar reduction of the parameter $q$ in the pores of the silica gel with pore diameter of $4 \mathrm{~nm}$ and a negatively charged surface was observed when the charge of the radical changes from negative to neutral and subsequently to positive [29]. 
With increasing acidity, the protonated form of the radicals and the silanol groups on the surface repel each other, and, consequently, the parameter $q$ increases. However, the point of zero charge (pzc) of the silicas surface is known to be some $\mathrm{pH}$ units lower than the $\mathrm{p} K_{a}$ value of the silanol groups: the pzc is equal to 3.6 and 2.8 for MCM-41 and for the MPS-F127 mesoporous silicate (similar to SBA-15), respectively [38,39]. Hence, the electrostatic interaction between the negatively charged surface of the material and the positively charged radicals $\mathrm{RH}^{+}$will dominate at this $\mathrm{pH}$ value. Therefore, the parameter $q$ increases less rapidly (Fig. 4), as expected from the positive charge of the surface and repulsion of radicals in the protonated form.

A comparison of the dependences of the parameter $q$ for NR R3 in the materials SBA-15 and $\mathrm{C}_{12}$ MCM-41 with $\mathrm{pH}$ (Fig. $4 \mathrm{a}$ and b) indicates that the number of NR molecules in the channels of $C_{12}$ MCM-41 is less than half compared to SBA-15. The reason for this difference is presumably the smaller channel size of $\mathrm{C}_{12} \mathrm{MCM}-41$. In the smaller channels the internal volume in the center of the channels decreases significantly and thus the parameter $q$ for R3 located in this volume is reduced as well. The observed effect of the channel diameter on this parameter for the NR used provides additional evidence for our assignment of this signal to the molecules of radicals located inside the channels. However, this conclusion is not in line with the results reported by Okazaki and Toriyama [32].

\subsection{NR size effect on the parameter $q$ in the MMS}

The differences in parameter $q$ for the large-and small-sized NR in the MMS studied can be explained as follows: If interaction of the surface groups with the radicals takes place via their nitrogen atoms in the third position of the imidazole fragment or of the side chain nitrogen, associated with the fourth position in imidazole ring, the parameters $q$ for all radicals would be approximately equal. The above-mentioned difference can only be explained by interaction with the surface of pyridine and phenyl fragments of R1 and R2, respectively. Except the hydrophilic silanol groups, the surface of the mesoporous molecur sieves has hydrophobic patches; this enables the sieves to sorb both ammonia and pyridine as well as benzene [40].

The presence of pyridine groups with $\mathrm{p} K_{a}=2.92$ provides $\mathrm{R} 1$ in weak-acid solutions with a better interaction with the positively charged surface of the silica support than R2 which possesses phenyl substituent. This results in a lower value of the parameter $q$ for NR R1 and in the shift of the curve minimum to lower $\mathrm{pH}$ values for the MCM-41 type molecular sieve (Fig. $4 \mathrm{~b}$ and c).

At a pH below 2, the curves for R1 and R2 in the channels $\mathrm{C}_{12}$ MCM-41 interchange their positions (Fig. 4b), i.e. the parameter $q$ for R1 is larger than that for R2. This may indicate a change in the charge of the pyridine group. In this case, the positively charged surface of $\mathrm{C}_{12} \mathrm{MCM}-41$ repulses the protonated pyridine fragments of $\mathrm{R} 1$, which results in an increase in mobility of some radical molecules. For R2, which possesses the phenyl substituents, this mechanism of interaction with the silica surface is lacking. For SBA-15 is has been reported that the amount of hydroxyl groups is smaller compared to MCM-41 as consequence of the synthesis at very low $\mathrm{pH}$ [40]. Therefore, the surface is more hydrophobic compared to the MCM-41 surface. As a consequence, the fraction of the R1 molecules interacting strongly with the surface decreases while the fraction of R2 increases. The analysis of the EPR signals of the radicals in the parent aqueous solutions shows that anisotropic rotational diffusion is dominating for the larger radicals $\mathrm{R} 1$ and $\mathrm{R} 2$, while the smaller radical R3 rotates isotropically [36,41]. Rotational anisotropy is caused by the presence of bulky pyridine and phenyl groups in position two of these radicals. As discussed above, at high $\mathrm{pH}(\mathrm{pH} \geqslant 9.5)$, only the spectra of the "fast motional" rad- icals have been observed (Fig. 2). This allows a comparison with the spectra of the corresponding radicals in the deprotonated form ( $\mathrm{pH} 8-9)$ in the parent aqueous solutions.

The model of rotational diffusion proved to remain invariable for the radicals R1 and R2. R3 exhibits isotropic rotation in solution and anisotropic reorientation in the channels of the ordered mesoporous materials. The observed change in the character of the rotation is caused by the diffusion of the radicals into the narrow channels of the silica support. The small diameter of the channels limits the mobility of R3 in the normal direction to the surface thus causing the observed anisotropy of its rotational diffusion. Of course, R1 and R2 with their diameter of about $0.8 \mathrm{~nm}$ (Table 1) experience the same limitations in mobility in the cross direction of the channel.

The lack of obvious differences in the spectra of these radicals in aqueous solutions and inside the channels of MMS at high pH suggests an orientation of the radicals' bulky substituents along the channels. The observed change in the EPR signal of the radical R3 also proves their location inside the channels of the mesoporous support.

\section{Conclusions}

The analysis of the EPR spectra of nitroxide radicals located in the solution and pores of the studied molecular sieves and the results of the radical retention by the MMS while washing with aqueous solution of $\mathrm{KCl}$ allow to understand the location and motion of these radicals inside the channels of the MMS studied in this work and to assess the effect of the channel nanosizes on the mobility of the nitroxide radicals. It is suggested that the pyridine and benzene fragments of the radicals interact with the silica surface. The presence of these substituents allows the radical molecules to interact both with the hydrophilic and hydrophobic patches of the surface. The observed similarity and differences in the behavior of the R1 and $\mathrm{R} 2$ radicals in the MMS allow to assess their ratios qualitatively. The information on a fraction of the "fast-motional" radical molecules in the sieve channels indicate the possibility of using both "fast and slow-motional" NR for estimation of the solution acidity inside the channels and near - surface electrical potential near the surface. These data are in a good agreement with the literature on the non-coincidence of the pzc of the silica surface and $\mathrm{p} K_{a}$ of silanol groups.

\section{Acknowledgements}

This work was supported by the Research Program of the Ministry of the Education of the Russian Federation (2007-2011). E.G.K. thanks the Program of Cooperation "Mikhail Lomonosov" between the Ministry of Education of Russian Federation and the German Service of Academic Exchanges (DAAD). We are grateful to Dr. G. Chandrasekar for assistance in the synthesis of MMS and their characterization.

\section{Appendix A. Supplementary data}

Supplementary data associated with this article can be found, in the online version, at http://dx.doi.org/10.1016/j.micromeso.2013. 05.019 .

\section{References}

[1] M. Klotz, A. Ayral, C. Guizard, L.J. Cot, Mater. Chem. 10 (3) (2000) 663-669.

[2] T.W. Wang, L.R. Dai, Chem. Lett. 11 (12) (2000) 1107-1110.

[3] V.M. Zaitsev, Complex-forming silicas, Folio, Kharkov, 2003.

[4] M. Teymouri, A. Samadi-Maybodi, A. Vahid, Int. Nano Lett. 1 (1) (2011) 34-37.

[5] A. Katiyar, S. Yadav, P.G. Smirniotis, N.G. Pinto, J. Chromatogr. A 1122 (2006) 13-20. 
6] V. Fenelonov, Sci. Siberia 30-31 (2001) 2316-2317.

[7] Y. Long, T. Xu, Y. Sun, W. Dong, Langmuir 14 (1998) 6173-6178.

[8] X.S. Zhao, G.Q. Lu, J. Phys. Chem. B 102 (1998) 1556-1561.

[9] X.S. Zhao, G.Q. Lu, A.K. Whittaker, G.J. Millar, H.Y. Zhu, J. Phys. Chem. B 101 (1997) 6525-6531.

[10] R. Ayler, Chemistry of Silica, in 2 parts, P.2, Mir, Moscow, 1982.

[11] L.S. Molochnikov, E.G. Kovalyova, I.A. Grigor'ev, A.A. Zagorodni, J. Phys. Chem. 108 (2004) 1302

[12] L.S. Molochnikov, E.G. Kovalyova, E.L. Golovkina, I.A. Kirylluk, I.A. Grigor'ev, Rus. Colloid. J. 69 (2007) 821-838.

[13] M.W. Støcker, V. Torbjørn, Adv. Colloid Interface Sci. 123 (2006) 17-32.

[14] J. Banys, M. Kinka, A. Meškauskas, J. Macutkevic, G. Völkel, W. Böhlman, V. Umamaheswari, M. Hartmann, A. Pöppl, Ferroelectrics 318 (2005) 201-207.

[15] V.B. Golubev, E.V. Lunina, A.K. Selivansky, Prog. Chem. 5 (1981) 792-812.

[16] I.A. Kirilyuk, A.A. Bobko, V.V. Khramtsov, I.A. Grigor'ev, Org. Biomol. Chem. 7 (2005) 1269-1274.

[17] I.A. Kirilyuk, T.G. Shevelev, D.A. Morozov, E.L. Khromovskih, N.G. Skuridin, V.V. Khramtsov, I.A. Grigor'ev, Synthesis 6 (2003) 871-878.

[18] M. Hartmann, S. Racouchot, C. Bischof, Microporous Mesoporous Mater. 27 (1999) 309-320.

[19] M. Hartmann, A. Vinu, Langmuir 18 (2002) 8010.

[20] A. Vinu, V. Murugesan, M. Hartmann, J. Phys. Chem. B 108 (2004) 73237330.

[21] A. Vinu, W. Böhlmann, M. Hartmann, J. Phys. Chem. B 108 (2004) 11496.

[22] A.N. Tihonov, Soros Ed. J. 1 (1998) 8-15.

[23] N.J. Polyansky, G.B. Gorbunov, N.L. Polianskaya, Methods for Investigation of Ion Exchangers, Khimia, Moscow, 1976 (in Russian).
[24] D.E. Budil, L. Sanghyuk, S. Saxena, J.H. Freed, J. Mag, Res. Series A 120 (1996) 155-189.

[25] L.I. Ancipherova, Atlas of spectra of Electron Spin Resonance of Spin probes and Labels, Nauka, Moscow, 1977.

26] G. Martini, M.F. Ottaviani, M. Romanelli, J. Colloid Interface Sci. 94 (1983) 105.

[27] M. Romanelli, M.F. Ottaviani, G. Martini, J. Colloid Interface Sci. 96 (1983) 373380.

28] G. Martini, Colloids Surf. 11 (1984) 409-421.

[29] G. Martini, M. Bindi, M.F. Ottaviani, M. Romanelli, J. Colloid Sci. 108 (1985) $140-148$.

[30] R.I. Samoilova, A.D. Milov, Yu.D. Tscvetkov, Russ. Colloid. J. 51 (1989) 725-730.

[31] P.P. Borbat, A.D. Milov, R.I. Samoilova, A.A. Suhoroslov, Russ. Colloid. J. 52 (1990) 341-345.

[32] M. Okazaki, K. Toriyama, J. Phys. Chem. B 109 (2005) 20068-20071.

[33] M. Okazaki, K. Toriyama, J. Phys. Chem. B 107 (2003) 7654-7658.

[34] M. Okazaki, K. Toriyama, J. Phys. Chem. C 111 (2007) 9122-9129.

[35] M. Okazaki, S. Anadan, S. Seelan, M. Nishida, K. Toriyama, Langmuir 23 (2007) 1215-1222.

[36] K. Morishige, K. Nobuoka, J. Chem. Phys. 107 (1997) 6965-6971.

[37] D.R. Cole, K.W. Herwig, E. Mamontov, Rev. Mineral. Geochem. 63 (2006) 313 362.

[38] G.V. Lisichkin, Chemistry of Graft Surface Compounds, Fizmathlit, Moscow, Russian, 2003.

[39] J. Deere, E. Magner, J.G. Wall, B.K. Holdnett, J. Phys. Chem. B 1069 (2002) 73407347.

[40] Yu D. Tretyakov, A.V. Lukashin, A.A. Eliceev, Prog. Chem. 73 (2004) 974-998.

[41] M. Okazaki, K. Kuwata, J. Phys. Chem. 88 (1984) 4181-4184. 